\title{
FIOS DE MEMÓRIA NA TEIA DO ESQUECIMENTO ${ }^{1}$
}

\author{
Antonio Edmilson Paschoal (UFPR) $)^{2,3}$ \\ antonio.paschoal@yahoo.com.br
}

Resumo: Este artigo toma como ponto de partida os significados conferidos por Friedrich Nietzsche aos conceitos de memória e de esquecimento, em associação com as ideias de perdão e de graça, com o objetivo de ampliar o horizonte interpretativo sobre o papel exercido por tais conceitos em alguns jogos políticos, como se verifica, por exemplo, na superação da Apartheid na África do Sul, por um lado, e do Regime Militar instalado no Brasil em 1964, por outro. A hipótese de trabalho é que os modos como se estabelecem as relações entre aqueles conceitos, nesses casos, expressam diferentes formas de assimilação do passado que podem resultar tanto no fortalecimento quanto no declínio de uma comunidade.

Palavras-chave: Memória; Esquecimento; Anistia; Comissão da Verdade; Nietzsche; Derrida.

\section{CONSIDERAÇÕES PRELIMINARES}

A investigação desenvolvida neste artigo corresponde ao desdobramento de alguns estudos e debates ${ }^{4}$ cujos resultados foram divulgados por meio de diversos veículos, dentre os quais pode-se nomear, a título de exemplo, dois artigos publicados anteriormente. No primeiro deles, intitulado "As formas do ressentimento na filosofia de Nietzsche" 5 , foi

\footnotetext{
${ }^{1}$ Recebido: 08-06-2021/ Aceito: 27-09-2021/ Publicado on-line: 18-11-2021.

${ }^{2}$ É professor adjunto na Universidade Federal do Paraná, Curitiba, PR, Brasil.

${ }^{3}$ ORCID: https://orcid.org/0000-0002-0843-4204.

${ }^{4}$ Em especial os debates com Daniel Omar Perez, que suscitou a preocupação com o tema da memória no âmbito dos debates sobre o esquecimento em Nietzsche, e com Jorge Luiz Viesenteiner, que me permitiu retomar com maior sutileza a relação entre Nietzsche e Hegel.

${ }^{5}$ PASCHOAL, A. E. As formas do ressentimento na filosofia de Nietzsche. I Revista Philósophos, Cont.
} 
colocado em relevo o problema do acúmulo desmedido de memórias, de impressões ruins derivadas de experiências passadas, apontando nesse excesso de memória uma forma de ressentimento. A patologia de uma vontade atada a um passado irrevogável. Um problema que encontraria sua solução num tipo de esquecimento que seria, assim, uma condição para o homem viver plenamente o presente. Para ser feliz.

No segundo artigo, intitulado "Contribuições para um debate sobre a justiça a partir da filosofia de Friedrich Nietzsche" ${ }^{6}$, foi acentuada a correlação entre ressentimento e justiça na obra do autor do Zaratustra, com foco especial na sua crítica à noção de justiça associada à ideia de vingança. Tendo em vista o papel capital do esquecimento para a superação do ressentimento, foram considerados, por um lado, a política que teve lugar na Europa na primeira metade do século XIX, como exemplo de uma política marcada pelo ressentimento ${ }^{7}$ e, por outro, apolítica do "arco íris" de Nelson Mandela, na África do Sul, como uma política que teria por pressuposto a superação do ressentimento ${ }^{8}$.

Acompanhando essa leitura da filosofia de Nietzsche, ganhou um destaque nesses artigos a ideia de esquecimento como expressão da força transbordante do indivíduo. Uma leitura que é extremamente produtiva, mas que também

\footnotetext{
V. 13, n. 01, Goiânia, jan./jun. 2008, p. 11-33.

${ }^{6}$ PASCHOAL, A. E. Contribuições para um debate sobre a justiça a partir da filosofia de Friedrich Nietzsche. Revista Philósophos, V. 18, n. 02, Goiânia, jul./dez. 2013, p. 43-59.

${ }^{7}$ Como referência principal foram tomados os apontamentos feitos por Peter SLOTERDIJK no livro. Zorn und Zeit. Frankfurt am Main. Suhrkamp, 2006.

${ }^{8}$ Foram consideradas de forma especial as análises de MOGLIORI, Maria Luci Buff. Horizontes do Perdão. Tese de doutoramento em filosofia apresentada ao Programa de Pós-Graduaçáo em Filosofia da PUCSP. São Paulo: PUCSP, 2007.
} 
pode produzir um tipo de expectativa demasiado elevada em relação ao esquecimento e, conforme a interpretação em curso, em relação ao perdão. Isto porque, sendo tomados como sinais de força e saúde tanto de um indivíduo quanto de uma comunidade tais conceitos poderiam remeter à vítima o papel de promover a solução do impasse criado por uma violência. Nesse sentido, de forma propedêutica, é importante mencionar, mantendo a filosofia de Nietzsche no horizonte, que aquele esquecimento que permite a felicidade não é comum entre os homens, nem uma obrigação moral. É possível mesmo afirmar que um esquecimento ativo, conforme veremos adiante, com toda a sua vitalidade, corresponde a uma espécie de utopia, vinculada a uma figura igualmente utópica, o nobre. Uma figura de linguagem que serve para regular nossas ações e que aparece no texto do filósofo como parte da estratégia de descrever um tipo psicológico e não propriamente de indicar pessoas que poderiam ser encontradas no cotidiano. Uma menção ainda mais importante de ser feita quando se trata do perdão, pois esse, conforme veremos, como uma moeda, tem seu valor justamente ao ser introduzido em certos cenários, por seus efeitos performativos, recolocando em cena o mesmo processo que levou à violência inicial.

Desse modo, se tais conceitos ganham um papel relevante quando se trata de suplantar o passado, eles precisam ser colocados em questão, em especial quando os episódios em pauta nesse passado vão além dos limites possíveis de assimilação por aquele esquecimento ou do que seria perdoável, e mais ainda quando se trata de fenômenos que ultrapassam os limites do indivíduo particular. Como se verifica em diferentes acontecimentos que foram absoluta- 
mente marcantes para a vida do homem em sociedade, como é o caso, por exemplo, da escravidão nas américas em geral e no Brasil em particular, dos campos de concentração na Europa, da Apartheid na África do Sul e também das ditaduras militares em países da América do Sul em geral e do Brasil em particular.

De fato, o perigo do uso de conceitos como esquecimento e perdão, e também o de "graça” nesses casos é bem grande. Por exemplo, quando eles se tornam instrumentos de uma ação política voltada para a mitigação dos acontecimentos passados, como se eles não tivessem relevância e fosse possível viver o presente sem considerá-los. $\mathrm{O}$ que exige uma atenção especial em relação a eles, em especial porque não possuem um caráter unívoco, mas ambíguo, sendo passíveis de diferentes interpretações e usos. Para atender a essa exigência, o presente estudo tem início com uma exposição acerca do caráter polissêmico e ambíguo desses conceitos, tendo em vista, inicialmente, os contornos apontados neles por Friedrich Nietzsche e também o modo como alguns deles são tensionados por Jacques Derrida, nos debates sobre a superação da Apartheid na África do Sul. O que deve fornecer o material necessário para avaliação do papel performático do teatro da superação da Ditadura Militar que teve no Brasil - uma avaliação que coloca em relevo, neste momento, o papel da memória como efeito e condição de saúde para uma comunidade.

\section{Ponto de PARTida. Nietzsche: O PERdÃO - UMA MOEDA FALSA}

O termo "perdão" (Verzeihen, Versöhnen, Vergeben), que 
aparece de forma abundante nas cartas de Nietzsche, é encontrado poucas vezes nos seus escritos. Ele surge, por exemplo, em Humano, demasiado humano, de forma irônica, numa apreciação sobre as vantagens daquele que ofende e depois pede perdão (Verzeihung) em comparação com àquele que concede o perdão, e que o faz como uma espécie de obrigação (HH 348); ${ }^{9}$ aparece também de forma indireta em Assim falou Zaratustra, na boca do sábio que propõe a reconciliação (Vesöhnen) consigo como uma virtude que promove o sono, pois, nas palavras do sábio, "dorme mal o não reconciliado” (ZA, Das cátedras da virtude).

Acentuando o caráter antagônico e paradoxal do perdão, o filósofo aborda o conceito de forma bem mais precisa em $\mathrm{O}$ andarilho e sua sombra, no aforismo chamado "seria possível perdoar"? (Ob man vergeben könne?), no qual explora a célebre frase de Jesus na cruz: "Pai, perdoa-lhes, não sabem o que fazem" (LC 23:34), conforme segue:

Como é possivel perdoá-los, se eles não sabem o que fazem? Não hão que perdoar. - Mas alguma vez um homem sabe inteiramente o que faz? E se isso é sempre no mínimo questionável, então os homens nunca têm o que perdoar uns aos outros, e exercer a graça (Gnadeüben) é algo impossivel para os mais sensatos. Por fim: se os malfeitores realmente soubessem o que fazem - então só teríamos o direito de perdoar se tivéssemos o direito de acusar e punir. Mas não o temos (HH II AS 68 - trad. modificada).

\footnotetext{
${ }^{9}$ As obras publicadas de Nietzsche serão referidas por meio de siglas já convencionadas, o que permite a localização do texto em diferentes edições das obras do filósofo, inclusive para leitores de fora do país. Também para os escritos de Hegel e Dühring, serão utilizadas siglas já convencionadas. Para as demais citações o padrão utilizado será o autor-data, com o sobrenome do autor, seguido do ano e do número da página. Nas referências, ao final do artigo, encontram-se as edições e as traduções utilizadas. Os textos em francês e espanhol são mantidos na versão original ao longo do artigo.
} 
O caráter paradoxal do perdão é evidenciado, também em Nietzsche, por meio do confronto entre perdão e esquecimento. Nos extremos desse paradoxo encontra-se, por um lado, o homem que não esquece e que, por decorrência, não poderia perdoar, pois se manteria prisioneiro de eventos passados que o torturam - como é o caso do homem do ressentimento, atado a um passado não resolvido, que o impede de viver plenamente o presente (GM II 1). Por outro lado, no extremo oposto, encontra-se o homem que esquece e que também não poderia perdoar porque não se lembraria daqueles eventos e, assim, não saberia o que perdoar - como é o caso da figura emblemática de Mirabeau, citado por Nietzsche, "que não tinha memória para os insultos e baixezas que sofria, e não podia desculpar (vergeben), simplesmente porque - esquecia” (GM I 10).

Refletindo sobre esse caráter paradoxal do perdão, Derrida o caracteriza como uma "experiência irredutível" ${ }^{10}$, (DERRIDA, 2012a, p. 10), na medida em que não poderia dizer respeito à falta mensurável, venal, "fácil de se perdoar" - pois, nesses casos, "eu não perdoo nada" -, mas àquilo que se encontra fora dessa esfera, onde temos justamente o que não pode ser alcançado pelo perdão, o "que é imperdoável” (DERRIDA, 2012b, p. 239).Em síntese, o perdão envolveria uma exigência impossível, sendo necessário apenas onde não é executável, fora das fronteiras da racionalidade; além de possuir um caráter "obsceno", pois, antes de

\footnotetext{
${ }^{10}$ Jean-Daniel Causse explora a impossibilidade do perdão para Nietzsche e Derrida, mostrando que, a seu modo, tanto "L'un et l'autre soutiennent que le pardon doit être retiré du champ des possibilités ordinaires” (2014, p. 128).
} 
alguém proferir a frase "eu perdoo", "eu perdoei” (DERRIDA, 2012b, p. 240) seria preciso ponderar se esse alguém teria o direito de perdoar e, mais ainda, se ao invés de perdoar, não deveria ter simplesmente esquecido.

Mais do que apenas paradoxal, contudo - voltando aos escritos de Nietzsche -, o termo "perdão" remete a valores fictícios. $\mathrm{O}$ que é explicitado pelo filósofo de forma tão dura quanto irônica na primeira dissertação da Genealogia da moral $^{11}$, quando faz uma genealogia do perdão, cuja origem remontaria àquela "oficina" onde se "fabricam ideais na terra". Uma oficina cujo maquinário se move em torno das ideias de retribuição e de pagamento (Auszahlung) e que é impulsionado pelos sentimentos de ódio, rancor e pela sede de vingança. Para o filósofo, o que caracteriza o funcionamento dessa oficina não é aquele excesso de "força plástica, modeladora, regeneradora, propiciadora do esquecimento", observada no caso de Mirabeau, que não podia "levar a sério por muito tempo seus inimigos, suas desventuras, seus mal feitos inclusive" (GM I 10), mas o seu oposto, uma fraqueza que, não podendo efetivar o seu ódio e rancor, denomina o seu "não-poder-vingar-se" como um "não-querervingar-se, talvez mesmo perdão (Verzeihung)" (GM I 14). Descortina-se, assim, naquele ambiente insalubre o teatro de uma absolvição que não apaga de fato o ocorrido, mas reafirma a própria lógica da retribuição e da sede de vingança $^{12}$. Motivo pelo qual Nietzsche designa aquele per-

\footnotetext{
${ }^{11}$ As afirmações feitas na seção 14 da primeira dissertação da Genealogiada moral são tão duras que sequer poderiam ser feitas por Nietzsche, que recorre a um personagem no texto, o "Senhor Curioso e Temerário" que é quem apresenta os meandros daquela oficina.

${ }^{12}$ Nietzsche reitera que aquele perdão não exclui o acerto de contas futuro, esperado no "juízo final", na parusia (AP 20:12-15), para quando é aguardado o "triunfo da justiça" sobre aqueles que Cont.
} 
dão produzido ali como uma moeda falsa (Falschmünzerei). Uma moeda cujo valor de uso não corresponderia à cifra que exibe. Uma mula, na linguagem da numismática. Uma peça cuja importância se dá mais por sua excentricidade do que pela efígie que apresenta.

É importante ressaltar ainda que, para Nietzsche, assumir a possibilidade do perdão implicaria, de imediato, no reconhecimento de outras ideias igualmente fictícias, como é o caso da noção de culpa e de pecado. Outros conceitos que ele não chancela em seus escritos, a não ser ao referir-se à interpretação religiosa do mundo que busca um "culpado" (GM III 15) para o sofrimento, um "inimigo mau" (GM I 10), contra o qual o sofredor dirige sua sede de vingança. Do mesmo modo como não ratifica a ideia de um sujeito que seria conhecedor de seus atos e das consequências deles, um sujeito que poderia avaliar a ação antes de realizá-la, em todas as suas consequências, e responder por ela, após a sua realização. Para o filósofo, essa figura não passaria de um produto da gramática que opera "como se houvesse um substrato indiferente que seria livre para exteriorizar ou não a força" (GM I 13), como se houvesse um agente que poderia "nomear as possibilidades morais e os movimentos interiores que antecedem uma ação" (A 116). Possibilidades que envolvem uma noção muito específica de responsabilidade associada à imputabilidade e que pertenceriam, em seu conjunto, segundo o filósofo, ao universo da ficçã $o^{13}$.

\footnotetext{
teriam sido "perdoados".

${ }^{13}$ Cabe aqui a ressalva, sobre a qual não poderemos discorrer neste momento, de que também a ideia de ficção possui diferentes conotações nos escritos de Nietzsche, em especial quando vincuCont.
} 


\section{A AMBIVALÊNCIA DA NOÇÃO DE $G R A C ̧ A$ NA SUPERAÇÃO DO DIREITO DE PUNIR}

Se o uso do conceito de "perdão" deve ser feito com ressalvas, tendo em vista seu caráter fictício e os problemas que o envolve, o uso do conceito de "graça", a princípio muito próximo da ideia de perdão, caso se considere o radical "dom" que compõe o termo, deve ser feito a partir de uma observação cuidadosa das nuances que o envolve do seu caráter ambivalente. Para ilustrar a ambivalência do conceito, pode-se tomar como um primeiro exemplo, no âmbito da filosofia de Nietzsche, o aforismo citado anteriormente de $\mathrm{O}$ andarilho e sua sombra (HH II AS 68), no qual o exercício da graça (Gnade-üben), associado ao perdão, é apontado como "algo impossível para os mais sensatos". Um segundo exemplo, no qual o filósofo faz um uso diferente do conceito, encontra-se na segunda dissertação da Genealogia da moral, onde o termo "graça" (Gnade) ganha lugar de destaque na sua argumentação, associado à ideia de superação de uma acepção retributiva de justiça.

Como é amplamente conhecido, na cultura ocidental, o termo "graça", no sentido de um beneplácito, de um ato gracioso, tem seu enraizamento primário no Cristianismo e é utilizado para designar a redenção dos pecados da humanidade. Oque ocorreria por uma dádiva, um "dom” conce-

lada à ideia de sujeito. De forma um pouco mais pormenorizada, desenvolvemos essa ideia em PASCHOAL, 2018. 
dido livremente por Deus aos homens ${ }^{14}$ que, a rigor, não poderiam pagar por suas faltas - o que tornaria o homem, com esse dom, agraciado de Deus, deixando de estar "debaixo da lei, mas sob a graça”. (Rom 8:15) Corresponde, assim, a uma redenção que decorre de um ato da misericórdia divina (Mateus 1, 21 e João 3,16), numa doutrina que envolve o pecado, a impossibilidade da expiação e a redenção como uma forma de reconciliação, que não deixa de ser uma troca, na medida em que "'outorgar a graça" se efetua no lugar de "fazer justiça" 15 .

De fato, não há como negar que o uso da ideia de "graça" nos escritos de Nietzsche remonta ao enraizamento do termo no solo do Cristianismo, assim como é certo que esse uso remete, também, ao modo como o termo aparece na filosofia de Hegel $^{16}$, em geral e no parágrafo 282 das Linhas Fundamentos da Filosofia do Direito, em particular ${ }^{17}$. Uma alusão que se evidencia ainda mais pela possibilidade, considerada por Nietzsche, numa linguagem hegeliana, de uma "autossuperação da justiça" (Selbstaufhebung der Gerechtigkeit - GM II 10) por um ato de graça. Tal proximidade do ter-

\footnotetext{
${ }^{14} \mathrm{O}$ que se efetivaria no sacrifício do Seu filho pelos pecados da humanidade (I Cor. 15).

${ }^{15}$ Nuevo Catecismo para adultos. Versión íntegra del Catecismo holandês. Barcelona: Editorial Herder, 1969, p. 277.

${ }^{16}$ É importante observar que a ideia de "graça" é explorada por Schopenhauer, por exemplo, no aforismo 70 de $\mathrm{O}$ mundo como vontade e representação, associada à ideia de um quietivo da vontade. Neste ponto, contudo, acompanhamos Nietzsche que afirma, em relação a Schopenhauer, que ele, assim como Darwin e também Dühring, seria um "evento alemão" (GC 357). Um evento de um espírito que surge de um dogma cristão "credo quia absurdum est [creio porque é absurdo]" e que até se mantém, "até dentro da lógica, pessimista". Uma lógica que se traduz, contudo, por meiodo "famoso princípio dialético-real com que Hegel, em seu tempo, ajudou o espírito alemão a conquistar a Europa - 'a contradição move o mundo, todas as coisas contradizem a si mesmas"' (A Prólogo 3), uma expressão do "espantoso golpe com que Hegel abalou todos os hábitos e vícios lógicos" (GC 357).

${ }^{17}$ Como é conhecido e acentuado por Isabelle WIENAND (2012, p. 111), Hegel mantém no conjunto de seu pensamento vários elementos próprios do Cristianismo.
} 
mo em relação ao Cristianismo e à linguagem de Hegel, verificada em especial no texto da Genealogia da moral (GM I 10), parece estar em evidente contradição com a sensatez esperada pelo filósofo ao falar dos limites da ideia de graça em $\mathrm{O}$ Andarilho e sua sombra (AS 68). O que torna essa passagem da Genealogia extremamente capciosa e passa a exigir de seu leitor uma atenção especial às nuances que comporta.

Para dar a devida atenção a tais nuances, é necessário ler o texto da Genealogia não como um desdobramento, mas como uma contraposição e uma alternativa a uma ideia de superação da justiça que é em grande parte sintetizada por Hegel. Nesse sentido, é importante considerar, inicialmente, alguns aspectos da tradição cristã-ocidental, que desempenham um papel decisivo no pensamento de Hegel, e que são criticados por Nietzsche na Genealogia. A saber, as ideias de liberdade da vontade (FD 4), de culpa (FD 90) e em especial a ideia de castigo tomada como algo justo em si (FD 100), pois suprimiria o crime por meio de uma "violência contra a violência" (FD 101), ou de uma "negação da negação” (FD 99). O que faria da punição uma supressão (Aufhebung $)^{18}$ do delito que conduziria ao restabelecimento do direito, que fora lesionado pelo infrator com o crime

\footnotetext{
${ }^{18}$ Traduzimos o termo "Aufhebung" por supressão quando diz respeito ao delito, que é suprimido pela punição e superação quando o termo é utilizado em relação à justiça, que é superada por ele. Cabe observar, contudo, que essa diferenciação é feita apenas para sinalizar uma nuance que nos interessa neste momento, do delito que é suprimido, apagado pela punição ou pela graça, e do direito que é resgatado, de algum modo, superado enquanto negação. Isto porque, a rigor, a expressão "Aufhebung" poderia ser traduzida tanto por "superação" quanto por "supressão", lembrando que ela possui uma riqueza semântica que comporta ainda a ideia de uma "elevação" e de "conservação", e que todos esses significados não podem ser desconsiderados quando se utiliza o termo, em especial se temos em vista a filosofia alemã.
} 
(FD 225). Um conjunto de ideias no qual a graça, como uma forma de indulto, teria um papel análogo ao do castigo na supressão (Aufheben) do delito, pois, também com a graça o delito seria suprimido e o direito restituído, como se tem com o castigo, porém, no caso, por meio de uma dádiva concedida pelo soberano (FD 282).

Analisando o significado dessas ideias no texto de $\mathrm{Ni}$ etzsche, e começando pela noção de culpa, deve-se observar que, na segunda dissertação da Genealogia da moral, o termo alemão Schuld, que pode ser traduzido tanto por "culpa" quanto por "dívida", tem uma conotação bem definida de dívida e não de culpa, e muito menos de uma culpa associada à ideia de pecado. Nesse texto, o filósofo opera uma naturalização da ideia Schuld, retirando-a de seu enraizamento religioso e mostrando que o termo Schuld, assim como o termo Strafe (castigo), tem sua origem nas obrigações contratuais primitivas derivadas do escambo, da troca de mercadorias. O termo remete, assim, a uma dívida que, naquele estágio da história da humanidade, conferia ao que fora prejudicado o direito de buscar uma compensação (Vergeltung), um pagamento que poderia ocorrer tanto na forma um valor monetário quanto de um dano causado ao devedor, um sofrimento que seria, então, aceito como uma moeda para o pagamento da dívida. Por sua vez, a graça, que surge após um longo desenvolvimento dessa ideia primitiva de justiça, no texto de Nietzsche, retoma a figura do "credor", que abre mão de uma compensação realizando, assim, "o seu mais nobre luxo: deixar impunes (strafloss) aqueles que o lesou (Schädiger)". Essa ênfase na ideia de abundância, associada à capacidade de suportar ultrajes e prejuízos, é fun- 
damental no texto quando o filósofo faz referência à comunidade que poderia, enfim, se perguntar: "'Que me importam meus parasitas?', diria ela. 'Eles podem viver e prosperar - sou forte o bastante para isso!'...”. (GM II 10). Uma argumentação, portanto, na qual há um evidente interesse em mostrar que termo "graça" pode ser utilizado sem uma associação direta com a ideia de perdão ou de remissão de uma culpa.

Quanto ao conceito de "superação" (Aufhebung), associado à ideia de graça, também ele ganha um sentido peculiar em Nietzsche, continuando com Hegel no horizonte, como um contraponto. De fato, como se tem no Cristianismo e em Hegel, também em Nietzsche, o uso do termo "graça" remete a uma interrupção da ordem habitual do direito, o que corresponde, em linhas gerais, à abstenção de uma cobrança ou de uma punição, por um ato de generosidade ${ }^{19}$. Em Nietzsche, contudo, a graça não equivale ao perdão, ao esquecimento e em especial - e este é o ponto que nuança o conceito - não restabeleceria o direito na sua forma inicial, retributiva, mas encetaria, como afirma Oswaldo Giacoia Junior, condições para "novos experimentos" (GIACOIA JR, 2010, p.107) no campo da justiça.

Neste ponto, é imprescindível observar que toda a argumentação do filósofo na segunda dissertação da Genealogia da moral constitui uma crítica à ideia de justiça entendida como a retribuição (Vergeltung) de um dano, ten-

\footnotetext{
${ }^{19}$ Uma exceção que também hoje é prevista na justiça punitiva: "o perdão da dívida, que isenta o devedor de pagamento, é previsto no Direito com o instituto da remissão, que é a liberação graciosa de uma dívida, ou a renúncia efetuada pelo credor que, espontaneamente, abre mão de seus direitos creditórios" (MIGLIORI, 2007, p. 23).
} 
do em vista a perspectiva daquele que foi lesado. Uma ideia capital na filosofia de Hegel (Wiedervergeltung - FD 101) e que é identificada por Nietzsche em Eugen Dühring, que aponta o limiar da justiça num sentimento de reação, de vingança, que seria natural ao homem que sofreu uma agressão. $\mathrm{O}$ que estabeleceria a origem da justiça para o campo do ressentimento, da vingança, do desejo de reparação daquele que foi ferido, prejudicado, ofendido ou detratado. Uma hipótese que estabelece a negação, vale dizer, a "negação [de uma]negação" (DÜHRING, 1865, p. 97) como sua ação capital e que, segundo Nietzsche, terminaria por "sacralizar a vingança em nome da justiça" (GM II $11)^{20}$. Nesse ponto, Dühring utiliza claramente a filosofia hegeliana que é, assim, indiretamente criticada no texto da Genealogia, quando Nietzsche se contrapõe à ideia de que a justiça teria sua origem num campo reativo, da negação, e que seria restabelecida, por uma negação da negação que constituiria a superação do delito.

Por sua vez, a utilização da noção de superação (Aufhebung) da justiça por Nietzsche, que corresponde a um ultrapassamento da própria justiça retributiva, deve ser compreendida tendo em vista o desdobramento da justiça, desde seus primórdios até aquele ponto de chegada no qual a graça se torna possível. Uma justiça que "iniciou com 'tu-

\footnotetext{
${ }^{20}$ A crítica a esse modo de conceber a justiça ganha corpo em vários textos de Nietzsche. É relevante, nesse sentido, a conhecida seção intitulada "Das Tarântulas", de Assim falou Zaratustra, na qual o filósofo se refere à ideia de justiça associada à vingança como um veneno que contamina todo o corpo social, em especial porque não ela se limita à busca de um pagamento por determinados danos sofridos, mas porque acaba por defender a padronização de um tipo de homem e a extirpação dos demais. A justiça, associada assim à dificuldade de suportar o diferente, termina por designar como justo um determinado tipo padronizado de homem e injusto qualquer tipo diferente dele. Cf.: PASCHOAL, 2013, p. 55.
} 
do é resgatável, tudo tem que ser pago', [e que] termina por fazer vista grossa e deixar escapar os insolventes (os falidos die Zahlungsunfähigen)". Nesse contexto, com termos hegelianos, mas numa perspectiva muito diferente da de Hegel, ele afirma que aquela justiça "termina como toda coisa boa sobre a terra, suprimindo a si mesma (sich selbst aufhebend)". (GM II 10) Na perspectiva aberta por Nietzsche, a ênfase se encontra na possibilidade de levar a justiça às suas últimas consequências e, assim, superá-la, não como um restabelecimento do direito retributivo lesado pelo delito, mas no sentido de abrir a possibilidade de uma justiça que se afasta do horizonte marcado pelo ressentimento. Por exemplo, numa justiça menos corretiva e mais voltada para a promoção da saúde da comunidade. Voltada para o futuro.

É certo que essa breve menção a Hegel - tendo em vista seu uso por Dühring e a crítica de Nietzsche - não apreende toda a potencialidade de seu pensamento no que se refere aos debates sobre o direito, o que deveria incluir uma cuidadosa distinção entre o direito abstrato e aquele que se tem no âmbito da sociedade civil, com uma atenção especial para a "evolução da liberdade" que se observa nesse estágio da evolução do espírito. Do mesmo modo como não explora os diferentes modos como Nietzsche ora se aproxima, ora critica elementos da filosofia hegeliana ${ }^{21}$. Mais do que isso, porém, interessa neste momento mostrar o modo

\footnotetext{
${ }^{21}$ Ainda a respeito de uma relação entre as filosofias de Hegel e Nietzsche, seria necessário considerar, por exemplo, de Karl Löwich: Von Hegel zu Nietzsche, Friedrich Kaulbach: Nietzsches Idee einer Experimentalphilosophie; Gilles Deleuze: Nietzsche et la philosophie; Jean Granier: Le problème de la vérité dans la philosophie de Nietzsche; Daniel Breazeale: "The Hegel-Nietzsche problem", r. F. Beerling: "Hegel und Nietzsche"; Werner Stegmaier: "Leib und Leben. Zum Hegel-Nietzsche-Problem" e "Nietzsches Hegel Bild"; Reinhart Maurer: "Hegel und das Ende der Geschichte" e "Die Aristokratische Alternative. Zur Nietzsches politischer Philosophie", entre outros.
} 
como Nietzsche faz uso da terminologia cristã-hegeliana metamorfoseando o significado inicial de alguns conceitos e introduzindo-os numa argumentação que tem propósitos diferentes daqueles almejados pelo filósofo nascido em Stuttgart. O que convém sobremaneira aos debates que se seguem nos próximos passos deste artigo, em especial na crítica à ideia de superação (Aufhebung). Assim, atento a esses detalhes e utilizando Hegel ainda como um contraponto privilegiado para Nietzsche configurar sua perspectiva sobre a superação da justiça, torna-se necessário considerar pontualmente a seção 282 das Linhas Fundamentais da Filosofia do Direito, onde Hegel tematiza a possibilidade de uma liberação graciosa do criminoso, utilizando para isso a expressão "direito de graça" (Begnadigungsrecht), nos seguintes termos:

Da soberania do monarca emana o direito de agraciar os criminosos, pois só dela provém aquela realização do poder do espírito de desfazer o ocorrido e apagar o crime no perdão e no esquecimento. (FD $282)^{22}$.

Nesse parágrafo, além da utilização do termo "graça”, dois aspectos são particularmente relevantes quando se faz o confronto dele com o texto da Genealogia. O primeiro diz respeito à "soberania do monarca", que é colocada em destaque no comentário ao parágrafo, onde Hegel afirma que "o direito da graça é um dos mais elevados reconhecimentos da majestade do espírito" (FD 282); o segundo, que

\footnotetext{
22 "Aus der Souveränität des Monarchen fließt das Begnadigungsrecht der Verbrecher, denn ihr nur kommt die Verwirklichung der Macht des Geistes zu, das Geschehene ungeschehen zu machen und im Vergeben und Vergessen das Verbrechen zu vernichten." (Grundlinien der Philosophie des Rechts, 282)
} 
aquela superação que desfaz o ocorrido, apaga o crime "no perdão e no esquecimento", o que reintroduz o tema do esquecimento, central para esta investigação.

Sobre o primeiro aspecto, que diz respeito à graça como um dom conferido por alguém que tem um excedente de poder, é possível afirmar que Nietzsche acompanha Hegel e também o Cristianismo - em especial ao considerar o benefício da graça como uma concessão feita por um poder absolutamente superior ao que produziu o dano, o que se tem com a ideia de uma evolução do espírito em Hegel e do fortalecimento da comunidade em Nietzsche. Para Hegel, a possibilidade da graça corresponderia à "realização do poder do espírito", permitindo reconhecer a majestade desse poder. $\mathrm{O}$ que explica o fato de que tal ideia não aparece, por exemplo, no âmbito do direito abstrato, uma das formas primárias do direito, mas torna-se possível apenas no momento em que o desenvolvimento da ideia de liberdade se realiza no Estado. Também para Nietzsche, embora não tenha no horizonte um desdobramento histórico do espírito, a graça é considerada como uma possibilidade que advém com uma evolução da justiça vinculada ao fortalecimento da comunidade. Ela está ligada ao crescimento do poder da comunidade e, mais ainda, à consciência desse poder, à "consciência de si", (GM II 10) que é condição para essa comunidade suavizar o direito penal e deixar passar seus insolventes.

Quanto ao segundo aspecto, que diz respeito tanto à ideia de "desfazer o ocorrido e apagar o crime" quando o fato de isso ocorrer "no perdão e no esquecimento", (FD 282) a divergência de Nietzsche com Hegel se evidencia inicialmente pelo fato, já mencionado que, na Genealogia, a 
"graça” não é associada à palavra perdão. Ela se acentua, porém, com a ideia, central em Hegel, de "desfazer o ocorrido e apagar o crime". O que equivale àquela negação do delito associada à ideia de sua supressão (Aufhebung), com a peculiaridade de que, no caso, seria a graça que apagaria o delito, restaurando o direito. Essa divergência, contudo, ganha uma evidência ainda maior com a associação entre graça e esquecimento que se tem no texto de Hegel, pois, no caso, a supressão corresponderia a apagar o ocorrido da memória e lança-lo no esquecimento. Um traço que não é observado no texto de Nietzsche, em que a graça não é associada a uma forma de esquecimento, entendido como um apagar da memória o ocorrido. Este ponto, contudo, merece uma atenção especial em função da polissemia do termo esquecimento em Nietzsche, com o destaque para o fato de que ele não se produz numa contraposição linear com a memória, como seria de esperar numa interpretação unívoca e contraposta desses conceitos em que as únicas opções seriam, por um lado, manter algo na memória, lembrar e, por outro, apagar os vestígios do ocorrido, esquecer.

\section{A POLISSEMIA DOS CONCEITOS DE ESQUECIMENTO E DE MEMÓRIA}

A ideia de esquecimento que aparece no parágrafo 282 das Linhas Fundamentais da Filosofia do Direito de Hegel está vinculada à ação do soberano, que "apaga o delito no perdão e no esquecimento". Ela corresponde a uma contraposição à memória na qual o esquecimento corresponderia a uma espécie de campo vazio no qual (in dem) seria lançado delito ou, ainda, a um instrumento por meio do qual o so- 
berano negaria o delito e restabeleceria o direito. Essa acepção, que aproxima esquecimento e perdão, será explorada por Derrida na sua crítica aos trabalhos da Comissão da Verdade e da Reconciliação da África do Sul e deverá ser útil também para a análise proposta, neste artigo, da Lei da Anistia, promulgada no Brasil no ano de 1979. Para viabilizar essa análise, contudo, será necessário considerar ainda alguns outros significados conferidos aos termos "esquecimento" e "memoria" e outras formas de relação entre eles, o que nos remete, novamente, à filosofia de Nietzsche.

Começando pelo termo "esquecimento", ele possui nos escritos do filósofo de Weimar ao menos duas acepções bem demarcadas. A primeira corresponde ao desaparecimento das impressões causadas na memória por eventos passados, numa espécie de desgaste dessas impressões, como se tem com uma moeda que, com o tempo, perde os contornos da efígie originalmente gravada nela. Trata-se, assim, de uma força inercial que deteriora as impressões passadas e que, a rigor, precisa ser freada, por exemplo, quando se quer tornar o homem um animal confiável, capaz de fazer promessas, em resumo, moralizado.

A segunda acepção de esquecimento corresponde à capacidade de assimilação pelo indivíduo dos sentimentos produzidos pelos eventos passados. Uma acepção que, ao certo, não era conhecida por Hegel, visto que aparece apenas no final do século XIX ${ }^{23}$, e que é caracterizada por Ni-

\footnotetext{
${ }^{23}$ As concepções de memória da vontade e de um ativo esquecimento são peculiares em Nietzsche e estão relacionadas com o seu envolvimento em debates com autores contemporâneos a ele, como é o caso de Hermann EBBINGHAUS (Über das Gedächtnis, de 1885) e também de Friedrich HERBART (Lehrbuch zur Psychologie, de 1816). Cf.: BRUSOTTI, Die "Selbstverkleinerung des Menschen'. Nietzsche-Studien, 21, 1992, p. 90 e também STEGMAIER, Nietzsches Genealogie der Cont.
} 
etzsche como um "esquecimento ativo". Um esquecimento que, nas palavras do filósofo, permitiria "um pouco de sossego, um pouco de tábula rasa da consciência, para que novamente haja lugar para o novo, sobretudo para as funções e funcionários mais nobres, para o reger, prever, predeterminar", sem o qual "não poderia haver felicidade, jovialidade, esperança, orgulho, presente”, (GM II 1). Tal acepção tem na ideia de digestão ou de assimilação pela alma (Einverseelung) a sua explicação mais elucidativa. Uma tese formulada no início da segunda dissertação da Genealogia da moral, onde o filósofo afirma que tal esquecimento

não é uma simples vis inertiae [força inercial], como crêem os superficiais, mas uma faculdade inibidora, ativa, positiva no mais rigoroso sentido, graças à qual o que é por nós experimentado, vivenciado, em nós acolhido, penetra tão pouco em nossa consciência, no processo de digestão (ao qual poderíamos chamar "assimilação psíquica"), quanto penetra nela todo o multiforme processo da nossa nutrição corporal ou "assimilação corporal”. (GM II 1 - tradução modificada).

Explorando essa a ideia de digestão, é plausível entenderas impressões e sentimentos produzidos pelas vivências passadas como um alimento, o material básico que uma vez assimilado, nutre o indivíduo e permite a ele "tornar-se o que é" ${ }^{24}$. Ao passo que o mal funcionamento do aparelho responsável por essa assimilação, como um aparelho digestivo, corresponderia uma espécie de indigestão ou uma dis-

\footnotetext{
Moral. Darmstadt: Wiss. Buchges., 1994, p. 133ss. Nesses debates deve-se incluir também RIBOT, Th. Les Maladies de la Mémoire. Dix-huitième èdition. Paris: Félix Alcan, Éditeur, 1906.

${ }^{24}$ Subtítulo da obra Ecce homo, na qual, a principio, o filósofo aponta justamente suas vivências, o modo como as assimila e como elas permitem a ele tornar-se o que é.
} 
pepsia e produziria uma espécie de desnutrição ${ }^{25}$. Trata-se, assim, de uma forma de estabelecer uma relação com o passado, na qual o modo como se assimila as impressões do que se passou é condição indispensável para o que se é no presente, tanto em termos de saúde quando de doença. Assim, o passado, como um alimento, eventualmente o único disponível, e também as sensações produzidas por ele, não pode ser descartado, como se fosse possível viver o presente sem considera-lo ${ }^{26}$.

Uma tal acepção de esquecimento não se contrapõe à memória, mas estabelece uma interessante relação com ela. O que obriga o filósofo a introduzir o tema da memória no mesmo parágrafo em que afirmara a necessidade do esquecimento. Naquele contexto, assim como se verificou em relação ao esquecimento, também o termo "memória" é apresentado tendo em vista duas acepções distintas. A primeira corresponde ao acúmulo produzido pela retenção inercial das impressões das vivências passadas. Ela corresponde ao "não-mais-poder-livrar-se da impressão uma vez recebida" que pode se tornar, mantendo a ideia de aparelho digestivo, um caso de "indigestão" anímica (GM II 1) factível de conduzir a uma expansão indesejada, a um inchaço do mundo interior - algo análogo ao que se tem quando o

\footnotetext{
${ }^{25}$ D'onde a importância, para o filósofo, do conhecimento do próprio estômago e, por conseguinte, daquilo que o fortalece ou que pode degradá-lo, explicitada por ele em EH, Por que sou tão inteligente, 1 e 2.

${ }^{26}$ É nesse sentido, fisiológico, que Nietzsche faz referência ao homem acometido pelo ressentimento como aquele que "não se sabe nada rechaçar, de nada se desvencilhar, de nada dar conta tudo fere", e que te seu mundo interior ocupado pela "impotência da vingança (sede de vingança), pelo revolver venenos em todo sentido" (EH I 6). É nesse sentido, também, que ele se refere ao " "homem forte e bem logrado" como aquele que "digere suas vivências (feitos e malfeitos incluídos) como suas refeições, mesmo quando tem de engolir duros bocados" (GM III 16).
} 
aparelho inibidor do esquecimento não funciona.

A segunda acepção para o termo "memória" é aquela que Nietzsche chama de "memória da vontade". Tal memória, assim como ocorre com o "ativo esquecimento", corresponde a uma faculdade (Vermögen). Uma faculdade "com cujo auxílio o esquecimento é suspenso em determinados casos". Diferentemente da memória inercial, ela corresponderia a "um ativo não-mais-querer-livrar-se" da impressão uma vez recebida. A um "prosseguir-querendo o já querido”. Uma disposição de manter a lembrança do passado, tendo em vista o caráter nutritivo dessas lembranças para o presente e também para o futuro do homem, como se tem naqueles casos em que os propósitos futuros são assegurados por meio de uma promessa. Quando é imprescindível que

entre o primitivo "quero", "farei", e a verdadeira descarga da vontade, seu ato, todo um mundo de novas e estranhas coisas, circunstâncias, mesmo atos de vontade, pode ser resolutamente interposto, sem que assim se rompa esta longa cadeia do querer. (GM II 1).

Diferentemente, portanto, de um simples "não-poderlivrar-se" das impressões passadas, essa memória não pode ser desconsiderada no processo de moralização dos costumes, pois é ela que faz sazonar no homem aquilo que vai ser chamado de sua "razão". (GM II 3) Num processo no qual não atua diretamente nem o esquecimento inercial, que precisa ser contido para ele se desenvolva, nem a memória entendida como um acúmulo desregrado de impressões passadas que, no seu extremo, como uma patologia de uma vontade presa no passado, poderia emperrar esse processo. Um decurso no qual atuam, antes, o esquecimento ativo e a 
memória da vontade, que são condições para o fortalecimento da comunidade, o que, por sua vez, é a condição que torna possível o luxo da graça.

Portanto, do mesmo modo como a ideia de graça em Nietzsche não poderia ser associada ao conceito de perdão, também não poderia vincular-se a um esquecimento que anularia o ocorrido, o passado, como se tem no texto de Hegel. Isto porque, para Nietzsche, o poder da comunidade se constrói justamente sobre uma memória que não apenas retém as impressões passadas, mas o faz tendo em vista o futuro. Nela o vínculo entre o passado e o futuro é estabelecido por meio da memória. $\mathrm{O}$ passado como matéria prima e promessa e o futuro como esperança de saúde e de realização. Um futuro anteriormente desejado- um "futuro anterior", na terminologia de Derrida (1984, p. 22) - e que deve dispor da justiça a seu serviço.

\section{OS LIMITES DO PERDÃO E A CRIAÇÃO DE UMA MEMÓRIA NA ÁFRICA DO SUL}

Tendo em vista os diferentes modos de se lidar com o passado passivos de serem expostos por conceitos polissêmicos e ambíguos e com a atenção voltada especialmente para a ideia de superação (Aufhebung) da justiça que poderia ser entendida como uma reafirmação do direito ou, num sentido oposto, permitir novas experiências no campo da justiça, passamos a considerar os debates sobre a ideia de superação da Apartheid na África do Sul, dando ênfase aos argumentos de Jacques Derrida, com o intuito, mais adiante, de avaliar alguns aspectos capitais da superação da Ditadura Militar que tem no Brasil. 
Dos debates sobre a superação da Apartheid na África do Sul, será considerada, inicialmente, de forma muito breve e pontual, a crítica de Derrida à ideia de reconciliação que marca os trabalhos da Comissão da Verdade e da Reconciliação, criada na África do Sul em 1995. Paralelo a essa crítica aos trabalhos da Comissão, será observado também o papel conferido à ideia de assimilação e de memória naquele processo.

O perdão praticado na África do Sul e a anistia que se seguiu a ele, teve como pressuposto um ritual no qual se dava o confronto daquele que receberia o induto, os agressores, com suas vítimas, num processo conduzido pela Comissão da Verdade e da Reconciliação. Um processo no qual ganha evidência, segundo Desmond Tutu, por um lado, a frivolidade com que pessoas foram assassinadas durante o regime da Apartheid e, por outro, a "magnanimité saissante et rassérénante, ainsique l'incroyable noblesse d'âme, de ceux qui ont souffert ce quíls ont souffert" (TUTU, p. 63).Como exemplo da força das pessoas simples da África do Sul e da capacidade delas para o perdão, Desmond Tutu aponta o caso de uma mãe que no confronto com os policiais que arrastaram seu filho com uma corda, afirma que não deseja que ele seja punido ou preso, mas o perdoa. "Je ne veux pas qu'on lui fasse quoi que ce soit. Je ne veux pas qu'il aille en prison. Je lui pardonne”. (TUTU, 1997, p. 67)

Crítico a esse processo, Derrida coloca em relevo que a reconciliação praticada nele teve por pressuposto uma concepção específica de perdão, vinculada, por um lado, ao pedido de perdão, à ideia de uma transformação do pecador, de sua conversão e, por outro, à magnanimidade daquele 
que sofreu a violência e que confere o perdão. (DERRIDA, 2004, p. 150) Portanto, uma ideia cristã de perdão, que se evidencia também no fato de Desmond Tutu, coordenador dos trabalhos da Comissão, ser bispo da Igreja Anglicana. $\mathrm{Na}$ sua análise desses trabalhos da Comissão, Derrida evidencia o alto preço imposto às pessoas que sofreram violências e foram confrontadas com seus algozes. Para ele, não seria de se esperar que as pessoas simples da África do Sul pudessem suportar a ideia de esquecer as torturas sofridas e a morte de entes queridos e, mais ainda, que pudessem perdoar os algozes colocados diante delas no ritual da reconciliação.

Desse modo, num sentido oposto ao exemplo apontado por Tutu, Derrida avalia aquela acepção idealizada de perdão e o ritual, o teatro, no qual ela é introduzida, tendo em vista o caso de uma mulher que teve o marido morto e que, diante da Comissão, no jogo das traduções do seu idioma para o inglês e do inglês para o francês (por Derrida), afirma: "Aucun gouvernement ne peut pardonner. (Silence.) Aucune commission ne peut pardonner. (Silence. ) Moi seule puis pardonner. (Silence.) Et je ne suis pas prête à pardonner" (DERRIDA, 2004, p. 138). Um pronunciamento que expressa, segundo Derrida, em termoscontraditórios ou confusos, um sofrimento único, que não poderia ser dito em palavras e que remeteria à impossibilidade do perdão. Acrescentando ainda que esse confronto, em muitos casos, correspondeu a um novo sofrimento imposto às vítimas, em especial no caso das mulheres violentadas, para as quais a dificuldade de se colocarem como testemunhas diante de seus algozes e da Comissão da Verdade se acentu- 
ava, quando a acusação aos seus algozes soava como uma "autoacusação" (DERRIDA, 2004, p. 146). O que não cicatrizaria, mas abriria ainda mais a ferida causada por aquela violência.

Do mesmo modo, também a superação praticada pela Comissão da Verdade, segundo Derrida, se manteria nos moldes hegelianos tanto por seu formato de uma negação da negação que reafirma o direito. A reconciliação que teve lugar no final da Apartheid seguiria, assim, a lógica da negação da negação, a lógica da superação (Aufhebung) que reafirma um modelo em crise ${ }^{27}$ com a peculiaridade, nesse caso, que a superação da Apartheid seria um capítulo do modo como o homem negro africano foi assimilado e introduzido no "processo civilizatório". Passando a tomar parte da "história universal", do mundo livre, por meio de sua elevação ao plano da consciência (DERRIDA, 2004, p. 129), na medida em que essa consciência seria a consciência europeia. Como parte desse processo, a superação da Apartheid terminaria por reafirmar a mesma lógica que produziu a Apartheid.

Não é pouco relevante, nesse sentido, o fato de o ato fundador da nova República Sul Africana se dar "par un "mot de réconciliation"”, segundo Derrida (2004, p. 113), tendo em vista que a palavra "reconciliação", como a supressão (Aufhebung) de um dano, remeteria em seu extremo ao espírito absoluto que, existente aí, contempla a si mesmo, é puro conhecimento de si mesmo. O que corresponderia ao vínculo estabelecido por Hegel, na Fenomenologia do

${ }^{27}$ DERRIDA, 2005, p.68. 
Espirito, entre a palavra "reconciliação" e o próprio "espírito existente" ${ }^{28}$. Para Derrida, portanto, na superação da Apartheid, o negro, antes segregado, teria acesso "à la liberté, à la clarté du jour dans le monde libre, à la conscience, à la loi, au droit", ou seja, "la réconciliation de l'Afrique du Sud libérée de 1'apartheid avec un discours chrétien ne serait qu'une preuve supplémentaire de cette histoire de l'esprit." (DERRIDA, 2004, p. 129) O que ficaria evidenciado, ainda, na expressão contida na nova constituição: "May God protect our people" (DERRIDA, 2004, p. 113) e que corresponderia, para Derrida, à manutenção do predomínio da cultura protestante, anglicana e sobretudo calvinista (dos Afrikaners) sobre as demais religiões e culturas. Numa lógica que não solicita, por exemplo, a ideia de companheirismo, que se teria por meio da palavra "abantu" (DERRIDA, p. 116), ou compreensão (não vingança, no caso), como "ubuntu" (p. 116), mas palavras como "verdade e reconciliação”.

\section{ANISTIA E SINAIS DE AMNÉSIA NA TERRA DA VERDADEIRA CRUZ}

Enquanto a Derrida interessa evidenciar os traços filosóficos - cristãos-hegelianos - da superação da Apartheid na África do Sul, a análise que se segue neste artigo tem como escopo principal verificar o modo como essa superação, no caso do Brasil, vincula-se a uma narrativa sobre o país que não é apenas efeito de jogos de poder, mas produtiva, per-

\footnotetext{
${ }^{28}$ Derrida refere-se à seção 493 da Fenomenologia do Espírito, onde se lê: "A palavra reconciliação é o espírito existente” (Das Wort der Versöhnung ist der daseiende Geist”).
} 
formativa, no interior deles.

Ao certo, não será possível, aqui, fazer uma análise da narrativa sobre o Brasil em seu conjunto ${ }^{29}$, nem avaliar o modo como aqui se deu a incorporação de diferentes povos no processo civilizatório, passando a ocupar lugares específicos na história do espírito. A análise concentra-se em algumas peculiaridades dessa narrativa que dizem respeito ao modo como se deu a superação do período obscuro da ditadura militar no país, tendo em vista, em especial, conforme veremos, o modo como nele a superação assume um papel performativo numa narrativa que ocupa a memória e promove o esquecimento.

A intervenção militar no Brasil foi justificada com o pretexto de reafirmar "os valores de preservação da família, da escola, da harmonia no trabalho, da propriedade, da obediência às normas políticas e jurídicas" (REZENDE, 2013, p. 39), que seriam os pressupostos para a garantia da ordem democrática. Assim, contrapondo-se a toda e qualquer ameaça àquela ordem e aos seus valores, o país foi governado, de1964 a 1985 , por militares que se sucederam no

\footnotetext{
${ }^{29}$ Uma narrativa que tem como seu marco inicial a carta de Pero Vaz de Caminha (disponível em: http://objdigital.bn.br/Acervo_Digital/Livros_eletronicos/carta.pdf. Acessado em maio de 2021), com sua descrição da Terra da Vera Cruz, e que se desdobra explicando a expansão territorial e econômica (cf., por exemplo, FURTADO, Celso. Formação econômica do Brasil. 32. Ed. São Paulo: Companhia Editora Nacional, 2005) em ciclos que compõem um processo no geral harmonioso, e que encobre, por exemplo, o papel do estupro na constituição dessa população, bem como o papel do roubo, do genocídio de povos indígenas, da violência inerente à escravidão, além da produção da miséria, como bases sobre as quais se deram aquela expansão e crescimento do que é conhecido hoje como Brasil. A literatura sobre essa expansão, e sobre a naturalização das diferenças sociais produzidas nela, bem como a expectativa pelo cumprimento de certos papéis por cada grupo social nesse conjunto, é explorada por vários sociólogos e historiadores, como é o caso, dentre os mais conhecidos, de Gilberto Freyre (Casa Grande e Senzala. Formação da família brasileira sob o regime da economia patriarcal. 48. Ed. São Paulo: Global, 2003) e Darci Ribeiro (O Povo Brasileiro. A formação e o sentido do Brasil. 2. Ed. São Paulo, Companhia das Letras, 1995).
} 
poder ao preço da censura, do desrespeito aos direitos humanos, torturas, mortes e desaparecimentos. No âmbito daquela narrativa, as ações do governo ou apoiadas por ele corresponderiam a uma reação a um perigo maior, a ameaça à ordem estabelecida. Desse modo, aquelas ações realizadas pelos militares restariam justificadas, pois só seriam negativas enquanto a negação de uma negação ${ }^{30}$. O que resulta na relativização das violências ocorridas no período e dificulta tanto a sua superação quanto o debate sobre elas.

Outo ponto importante para esse debate é o fato de que o fim do período militar não se deu como uma ruptura ou por um reconhecimento do caráter perverso dos eventos conduzidos pelos dirigentes do país naquela época, mas por um realinhamento político no qual as forças que dominaram o país naquele período se mantiveram ligadas ao poder, ou muito próximas dele, mesmo após o fim do regime militar, em 1985. Vale notar, nesse sentido, que o processo de abertura política que conduz ao fim do regime de exceção vivido no período foi conduzido pelos próprios militares, que visavam, assim, a manutenção, após o fim da ditadura, dos valores pregados por ela e a formação de uma consciência social favorável ao sistema instaurado em 64 . O próprio presidente João Batista Figueiredo, último governador militar do país, se apresentava como artífice desse processo, deixando claro que ele deveria ter, "como um de seus elementos fundantes, a subordinação de toda e qualquer mudança à continuidade dos propósitos de organização social

\footnotetext{
${ }^{30}$ Acompanhando, assim, formulações muito elementares da ideia de justiça que se tem, por exemplo, com Eugen Dühring (Op. cit., 1865, p. 97). O que terminaria, segundo a perspectiva de Nietzsche, e especialmente nesse caso, por "sacralizar a vingança em nome da justiça" (GM II 11).
} 
postos pelo movimento militar" (REZENDE, 2013, p. 326). O que era assegurado pela ideia da conciliação nacional, a qual fora endossada, de certo modo, pela chapa de "oposição” nas eleições indiretas de 1985. Não é de pouca importância o fato de que o primeiro presidente civil que assume o governo após aquele período, José Sarney, era egresso da Aliança Renovadora Nacional, o partido criado em 1965 para dar sustentação política aos militares no poder ${ }^{31}$.

Foi, portanto, como parte de uma "transição pacífica", que entrou em cena no país a ideia de redenção e de graça no teatro da superação da ditadura. O que ganha corpo por meio da lei de 28 de agosto de 1979, que concedia "anistia a todos quantos, no período compreendido entre 02 de setembro de 1961 e 15 de agosto de 1979" teriam cometido "crimes políticos", mas, também aos servidores e militares, colocando no mesmo patamar tanto os que construíram a ditadura e torturaram quanto os que lutaram contra ela - e foram torturados. Desse modo, foi concedido um induto, sem o reconhecimento da culpa, sem especificar o crime e sem indicar seus autores, rompendo com a prerrogativa básica de que "pour pardonner, il faut savoir ce qui s'est déroulé" (TUTU, 1997, p. 70). Uma peça tão confusa quanto performativa, pois com a Lei da Anistia, o discurso de apaziguamento ganhava contornos de uma realidade de direito incontestável, que atuava para a produção de uma paz pública assentada no esquecimento dos episódios violentos ocorridos durante a ditadura militar.

\footnotetext{
${ }^{31}$ Não é de pouca importância o fato de que a intervenção militar segue pairando como uma possibilidade sempre presente no debate político no país, em especial como um argumento extraordinariamente forte nas mãos da extrema direita.
} 
Se na memória individual das vítimas a violência produz marcas inapagáveis, em termos mais amplos, enquanto um fenômeno que perpassa o corpo social, a memória desses fatos torna-se um campo de disputa, no qual parece predominar a narrativa produzida sobre aqueles fatos e não a lembrança deles. O que se traduz, por exemplo, no fato de, em 2021, a data da implantação do regime militar, do golpe militar de 01/04/1964, como o dia da "Revolução", ter sido celebrada como um feriado nacional de ponto facultativo $^{32}$. O oposto do que se tem na África do Sul, onde a disposição de se construir uma memória é feita em eventos destinados a impedir que as lembranças das violências sejam apagadas da memória coletiva. A começar pela comemoração como um feriado nacional, o Dia da Reconciliação, 16 de dezembro; além de instituições mantidas com essa finalidade, como é o caso do "District Six Museum", criado em 1994, para retratar a remoção da população negra do bairro "District Six, durante a Apartheid. Muito significativo também, quando se tem no horizonte uma comparação com o Brasil, é o caso da Ilha de Robben, onde Nelson Mandela e outros militantes do período da Apartheid ficaram presos e que é hoje preservada como um museu aberto ao público, ao passo que no Brasil a Ilha das Pedras Brancas, para onde foram enviados vários presos políticos durante o período militar, encontra-se abandonada ${ }^{33}$.

32 Em 2021 a data ganhou o status de feriado, com ponto facultativo Cf.: https://www.in.gov.br/en/web/dou/-/portaria-me-n-3.776-de-31-de-marco-de-2021-311666188. Acessado em 10/05/21.

${ }^{33}$ Cf. matéria disponível em: https://www1.folha.uol.com.br/cotidiano/2019/05/tombada-pelopatrimonio-ilha-que-abrigou-presidio-na-ditadura-esta-abandonada.shtml. Acessado em $15 / 05 / 21$. 
Nesse sentido, ainda, vale registrar que, mesmo o propósito de "examinar e esclarecer o quadro de graves violações de direitos humanos praticadas,[...] a fim de efetivar o direito à memória e à verdade histórica e promover a reconciliação nacional”, foi estipulado apenas décadas depois do fim do regime militar, pela Lei no 12.528 , de 18 de novembro de 2011. Uma lei que resultou de uma demanda que ganhou expressão apenas em dezembro de 2009, no âmbito da 11a Conferência Nacional dos Direitos Humanos, reunida em Brasília, que recomendou a constituição de uma Comissão Nacional da Verdade, criada pela lei 12.528/2011 e instalada em 16/05/2012.

Se por um lado, ao referir-se à Comissão da Verdade instalada na África do Sul, Derrida confere grande importância ao termo "reconciliação" (DERRIDA, 2004, p. 113), é interessante observar, por outro, que no caso da Comissão instalada no Brasil o termo não aparece. Em seu lugar, ao lado do termo "verdade" encontra-se a palavra "nacional". O que é extremamente significativo para compreender essa Comissão, tendo em vista o contexto político no qual ela foi criada e as concessões que precisou fazer para poder existir. "Nacional", a comissão não pode significar um perigo à ordem estabelecida. Não pode ameaçar a nação e, muito menos, fundar uma nova nação, como se tem na África do Sul. Seu objetivo se limita a estabelecer um compromisso para que aquelas violações pontuais não voltem a se repetir. De fato, ela teve de enfrentar, desde sua criação, reações contrárias por parte da sociedade civil, dos militares e do próprio governo. Reações que resultaram, por exemplo, na descaracterização de seu propósito inicial, como se observa de forma sutil, pela ampliação do período analisado 
pela Comissão que passaria a abranger o interstício de 1946 a 1988, e não 1964 a 1985, que foi o período da intervenção militar, e em especial na revisão e enfraquecimento do eixo da Comissão intitulado "Direito à memória e à verdade" (Relatório CNV, p. 20), que deveria se ocupar da narrativa da violência ocorrida naquele período.

Contudo, embora tenha sido instaurada quase trinta anos depois dos fatos ocorridos, e fora obrigada a se mover no âmbito de uma margem de manobra muito restrita, o fato é que a Comissão, que não condicionou seus trabalhos ao perdão por parte das vítimas, permitiu aos familiares dos mortos e desaparecidos, desafiar a "recusa do governo em admitir a prática de graves violações de direitos humanos" (CNV, Relatório, p. 23). Em termos mais amplos, ela trouxe "para o presente, através dos inúmeros depoimentos das vítimas" (TORTATO, 2018, p. 69), a experiência da tortura. Nesse sentido, a Comissão atuou fortemente no jogo das narrativas, introduzindo nele relatos que foram construídos a partir de uma meticulosa arqueologia que chegou a corpos enterrados em cemitérios clandestinos, exumou cadáveres, revelando o destino de vários desaparecidos durante o regime $^{34}$.

Em linhas muito amplas, pode-se dizer que esse trabalho arqueológico constituiu um importante fator na labuta contra o esquecimento. Esse rememorar, contudo, apesar de ser uma experiência complexa e dolorosa, conforme já

\footnotetext{
${ }^{34}$ Conferir o Relatório da Comissão Nacional da Verdade, em especial a partir da página 290. Também a Secretaria Nacional de Direitos Humanos atuou ativamente nesse sentido, como ficou registrado, por exemplo, em: https://epoca.globo.com/tempo/noticia/2015/06/investigacaomostra-que-ainda-ha-corpos-de-vitimas-da-ditadura-no-cemiterio-de-perus.html. Acessado em 15 de maio de 2021.
} 
foi registrado por Derrida, não aprofunda o rancor e o ressentimento, mas permite um tipo de assimilação que, mantidas as devidas ressalvas, pode ser descrito pela ideia de uma assimilação anímica, de um esquecimento "ativo". O que está necessariamente vinculado à memória que se delineia nesse contexto, como produto de uma "vontade" ${ }^{35}$. Fatores que, associados, são indispensáveis não apenas para o luto, ou como uma promessa de que tais episódios não voltarão a acontecer no futuro, mas para um conhecimento de si que permite a experiência de si no presente. Tendo em vista, por exemplo, o quão frágil é a base sobre a qual se constrói a democracia no país.

Nesse sentido, apesar de sua natureza tímida e de não ter de fato se imposto aos militares, que em diversas ocasiões se recusaram a comparecer às audiências, a Comissão teve resultados que incluíram várias audiências públicas e investigações que permitiram a produção de um longo relatório que foi entregue em 10/12/2014 à então presidente Dilma Rousseff, no qual se concluía que no período analisado aconteceram "crimes contra a humanidade", em especial por conta do "contexto social generalizado de violações" como tortura, morte, desaparecimento e violência sexual.

Contudo, a despeito desses resultados, pode-se observar ainda na memória coletiva a força e mesmo o predomínio das narrativas produzidas pelas forças favoráveis ao princípio da indulgência irrestrita e da construção de uma "paz

\footnotetext{
${ }^{35}$ É importante apontar aqui a possibilidade não explorada neste artigo, de ampliar esse debate tendo em vista a questão da memória em Hannah Arendt, o que é indicado, por exemplo, por Miguel Angel BARRENECHEA e Mário José Dias no artigo intitulado "Entre a memória e a política: Nietzsche e Arendt na atualidade" (2013).
} 
pública" por meio da estratégia que consiste em tornar o acontecido em um não acontecido. Em apagar os traços elementares que permitiriam a construção de uma memória e a "apreciação da realidade e gravidade dos fatos" (MIGLIORI, 2007, p. 30). Ilustra essa predominância, o modo como foi mantida a lei da Anistia, por exemplo, diante da tentativa frustrada de revisão dessa lei que ocorre em 2010, quando a matéria foi apreciada pelo Supremo Tribunal Federal que se posicionou contra a revisão, mesmo diante de recurso feito à Corte Internacional de Direitos Humanos. Ele se evidencia também nas tentativas sem sucesso, em 2014, de mudar a Lei da Anistia, pois tanto ela, quanto a "prescrição", "constituem obstáculos para o processamento dos crimes contra a humanidade" (CNV, p. 30).

Constitui ainda um argumento a favor desse predomínio o fato mais elementar de o atual presidente do país, eleito com mais de 55 milhões de votos, ser conhecido por sua militância, desde a época em que era Deputado Federal, contra os trabalhos da Comissão. Uma figura célebre por suas posições favoráveis em relação aos governos militares e por suas afirmações irônicas sobre as violências cometidas no período, o que se evidenciou, por exemplo, nas homenagens que fez ao coronel Carlos Alberto Brilhante Ustra ${ }^{36}$, um dos mais violentos e sádicos torturadores do sistema de repressão do período e que escarneceu os trabalhos da Co-

\footnotetext{
36 Cf. matéria disponível em: https://noticias.uol.com.br/politica/ultimasnoticias/2019/08/07/bolsonaro-vai-receber-viuva-de-torturador-da-ditadura-nesta-

quinta.htm?cmpid. Acessado em 15/05/21. Cf. também: https://congressoemfoco.uol.com.br/direitos-humanos/onze-declaracoes-de-bolsonaro-emdefesa-da-ditadura/. Acessado em 15/05/21.
} 
missão Nacional da Verdade. Ou ainda por seu total desrespeito para com os desaparecidos do período militar, o que se revela, por exemplo, no fato de ter ironizado recentemente, em 2019, o desaparecimento de Fernando Santos Cruz, ocorrida em março de 1973, logo após a sua prisão no Destacamento de Operações de Informação - Centro de Operações de Defesa Interna (DOI-CODI), um órgão de repressão do governo militar ${ }^{37}$.

\section{7. ÚlTIMAS CONSIDERAÇÕES}

Se o jogo político segue muitas vezes por caminhos obscuros, isso não significa que ele seja um jogo fechado, mas um jogo aberto, no qual ideias como esquecimento e memória têm papel preponderante. Considerar essas ideias, e suas diferentes utilizações, em associação com outras ideias como "reconciliação", “anistia”, "perdão", "indulgência”, "graça”, implica em reconhecer o caráter ambivalente e polissêmico delas, como se evidencia na filosofia de Nietzsche

\footnotetext{
${ }^{37}$ Cf. matéria disponível em: https://www1.folha.uol.com.br/poder/2019/07/surpresos-aliados-emilitares-tentam-identificar-foco-de-acoes-intempestivas-de-bolsonaro.shtml. Acessado em 15/05/21. Inúmeros outros episódios poderiam ser indicados nesse sentido. É significativo, por exemplo, o fato de o mesmo Presidente da República ter substituído por militares e por membros de seu próprio partido, quatro dos sete membros da Comissão Especial Sobre Mortos e Desaparecidos Políticos, (Cf. matéria em: https://oglobo.globo.com/brasil/bolsonaro-poe-militaresintegrantes-do-psl-na-comissao-de-mortos-desaparecidos-politicos-

23847049?fbclid=IwAR3ZTgFvVR78uCo8Jjr60FbatDbBzF9Rev7ZqB7k1_XM9zOWaaURCZ _73xk. Acessado em 15/05/21. E também: https://noticias.uol.com.br/politica/ultimasnoticias/2019/08/01/assessor-de-damares-e-militares-os-nomeados-na-comissao-dedesaparecidos.htm. Acessado em 15/05/21) uma comissão ligada à Secretaria de Direitos Humanos, criada em 4 de dezembro de 1995 (Lei no 9.140) com o intuito de "proceder o reconhecimento de pessoas mortas ou desaparecidas em razão de graves violações aos direitos humanos ocorridas após o golpe civil-militar".(https://cemdp.sdh.gov.br.) Mais importante, contudo, é o fato de que Jair Bolsonaro se mantém na Presidência, com apoio de boa parcela da população, a despeito dos abusos cometidos.
} 
e também na crítica de Derrida à reconciliação que se tem na superação da Apartheid na África do Sul.

De fato, no cenário político esses conceitos podem cumprir diferentes papéis, em especial quando se trata de superar períodos de extrema violência. Nesses casos, como exemplifica a história recente do Brasil, eles permitem caracterizar certos propósitos, como se tem no caso do uso performativo do esquecimento em associação com a ideia de uma indulgência irrestrita, voltada para legitimar uma configuração de poder e manter a vítima na condição de vítima. Eles permitem também avaliar trabalhos de diferentes Comissões da Verdade que, no caso do Brasil, a despeito das críticas possíveis, ao lançar mão de um trabalho arqueológico, permitiu o resgate de uma memória que diz respeito não apenas às vítimas diretas da violência, mas também o corpo social como um todo, na medida em que essa memória, por mais que comporte horrores e problemas muito difíceis de serem solucionados, constitui o substrato mais importante para construção do presente e para divisar um futuro no qual ao menos esses erros não se repitam.

Um trabalho que considera diferentes modos de relação com o passado, dentre os quais ganha relevo a memória e o esquecimento como expressão da capacidade ou dificuldade de uma comunidade em assimilar esse passado. Um problema que não encontra na literatura específica uma solução simples, pois, do mesmo modo como se tem no círculo vicioso de um corpo fraco que não assimila alimentos e que se enfraquece ainda mais, também uma comunidade que não consegue cultivar uma memória pautada pela vontade, dificilmente poderá sazonar frutos saudáveis, como se tem no caso do Brasil, no qual se tem 
uma frágil democracia que precisa ser refundada inúmeras vezes, na medida em que sistematicamente perde seus fios de memória na grande teia do esquecimento.

Abstract: This article takes as a starting point the meanings given by Friedrich Nietzsche to the concepts of memory and forgetfulness, in association with the ideas of forgiveness and grace, in order to broaden the interpretative horizon on the role played by such concepts in same games politicians, as seen, for example, in overcoming Apartheid in South Africa, on the one hand, and the Military Regime installed in Brazil in 1964, on the other. The working hypothesis is that the ways in which the relationships between those concepts are established, in these cases, express different forms of assimilation from the past that can result in both the strengthening and the decline of a community.

Keywords: Memory; Forgetfulness; Amnesty; Truth Commission; Nietzsche; Derrida.

\section{REFERÊNCIAS}

\section{A BÍBLIA DE JERUSALÉM. São Paulo: Edições Paulinas, 1973.}

BARRENECHEA, Miguel Angel \& DIAS, Mário José. Entre a memória e a política: Nietzsche e Arendt na atualidade. Cadernos Nietzsche 33, p. 301-326, 2013.

BRASIL. Comissão Nacional da Verdade. Relatório / Comissão Nacional da Verdade. Vol. 1. Brasília: CNV, 2014.

BRUSOTTI, Marco. Die "Selbstverkleinerung des Menschen'. Nietzsche-Studien, 21, 1992.

CAUSSE, Jean-Daniel. Nietzsche, Derrida et l'impossible 
possibilite du pardon. In La passion de la grâce. Mélanges offerts à André Birmelé, édité par Michel DENEKEN et Elisabeth PARMENTIER. Genève: Labor et Fides, 2014, p. 127-136.

DERRIDA, Jacques. Otobiographies. L'enseignement de Nietzsche et la politique du nompropre. Paris: Éditions Galilée, 1984.

. História da mentira: prolegômenos. Estudos Avançados, Vol. 10, n. 27, p. 7-39. São Paulo, maio/ago. 1996.

. Versöhnung, ubuntu, pardon: quel genre? Le Seuil: "Le Genre humain". Verité, reconciliation, reparation. N. 43, p. 111-156, 2004.

. O perdão, a verdade, a reconciliação: qual gênero? In: NASCIMENTO, E. (org.). Jacques Derrida: pensar a desconstrução. Trad. Evando Nascimento. São Paulo: Estação Liberdade, 2005, p. 75.

- Pardonner. L'impardonnable et l'imprescriptible. Paris: Galilée, 2012a.

. Uma certa possibilidade impossível de dizer o acontecido. Coleção Jacques Derrida. Maiêuticar. 2012b, p. 231-251.

DÜHRING, Eugen. Der Werth des Lebens. Breslau: E. Trewendt, 1865.

HEGEL, G. W. Phänomenologie des Geistes. Werke 3. 2. ed. Frankfurt am Main: Suhrkamp, 1989a.

. Grundlinien der Philosophie des Rechts. Werke 7. 2. ed. Frankfurt am Main: Suhrkamp, 1989b. 
GIACOIA JR., Oswaldo. A autosupressão como catástrofe da consciência moral. Estudos Nietzsche, Curitiba, v. 1. N. 1: 73-128, jan./jun. 2010.

GOMES, Lucas Fraga. Autossupressão da moral e do perdão. Nietzsche e Derrida. Vitória, Dissertação de Mestrado - UFES, 2019.

MIGLIORI, M. L. Buff. Horizontes do Perdão. Tese de doutoramento em filosofia apresentada ao Programa de Pós-Graduação em Filosofia da PUCSP. São Paulo: PUCSP, 2007.

NIETZSCHE, Friedrich. Kritische Studienausgabe (KSA) Herausgegeben von Giorgio Colli und Mazzino Montinari. 15 vol. München/Berlin/New York: dtv/Walter de Gruyter, 1988.

. Humano, demasiado humano II. Trad. Paulo César de Souza. São Paulo: Companhia das Letras, 2008.

- Aurora. Reflexões sobre os preconceitos morais. Trad. Paulo César de Souza. São Paulo: Companhia das Letras, 2004.

A gaia Ciência. Trad. Paulo César de Souza. São Paulo: Companhia das Letras, 2001.

. Além do bem e do mal.Trad. Paulo César de Souza. São Paulo: Companhia das Letras, 1992.

. Genealogia da moral. Trad. Paulo César de Souza. São Paulo: Companhia das Letras, 1998.

. Ecce homo. Trad. Paulo César de Souza. São Paulo: Cia das letras, 1995. 
Nuevo Catecismo para adultos. Versión íntegra del Catecismo holandês. Barcelona: Editorial Herder, 1969

PASCHOAL, A. E. As formas do ressentimento na filosofia de Nietzsche. In: Revista Philósophos, V. 13, n. 01, Goiânia, jan./jun. 2008, p. 11-33.

Contribuições para um debate sobre a justiça a partir da filosofia de Friedrich Nietzsche. Revista Philósophos, V. 18, n. 02, Goiânia, jul./dez. 2013, p. 43-59.

- Da crítica de Nietzsche ao sujeito ao sujeito de sua crítica. In: Cadernos Nietzsche vol. 39 no.1 São Paulo Jan./Abr. 2018, p. 93-119.

REZENDE, Maria José de. A ditadura militar no Brasil: repressão e pretensão de Legitimidade - 1964-1984. Londrina: Editora da UEL, 2013.

RIBOT, Th. Les Maladies de la Mémoire. Dix-huitième èdition. Paris: Félix Alcan, Éditeur, 1906.

SLOTERDIJK, Peter. Zorn und Zeit. Frankfurt am Main. Suhrkamp, 2006.

STEGMAIER, W. Nietzsches Genealogie der Moral. Darmstadt: Wiss. Buchges., 1994.

TUTU, Desmond. Pas d'amnistie sans vérité. Entretien avac l'achevêque Desmond Tutu In. Esprit: Revue internationale, n. 238, décembre 1997, pp. 63-72.

TORTATO, Amanda Ribeiro. Lei da Anistia: Justiça e Perdão em Jacques Derrida. Revista Ágora. n. 28, p. 6174. Vitória, 2018. 
Antonio Edmilson Paschoal

WIENAND, Isabelle. Reconciliação no pensamento de Nietzsche? In: Cadernos Nietzsche, Vol. 31, 2012, p. 107125. 